\title{
PICTORIAL COMMUNICATION: PICTURES AND THE SYNTHETIC UNIVERSE
}

\author{
Stephen R. Ellis \\ NASA Ames Research Center \\ Moffett Field, California \\ and \\ U. C. Berkeley School of Optometry \\ Berkeley, California
}

\section{SUMMARY}

Principles for the design of dynamic spatial instruments for communicating quantitative information to viewers are considered through a brief review of the history of pictorial communication. Pictorial communication is seen to have two directions: 1) from the picture to the viewer and 2) from the viewer to the picture. Optimization of the design of interactive instruments using pictorial formats requires an understanding of the manipulative, perceptual, and cognitive limitations of human viewers.

\section{PICTURES}

People have been interested in pictures for a long time (fig. 1). This interest has two related aspects. On one hand we have an interest in the picture of reality provided to us in bits and pieces by our visual and gross body orienting systems-and their technological enhancements. Indeed, Western science has provided us with ever clearer pictures of reality through the extension of our senses by specialized instruments.

On the other hand, we also have an interest in pictures for communication, pictures to transmit information among ourselves as well as between us and our increasingly sophisticated informationprocessing machines. This second aspect will be our prime focus, but some discussion of the first is unavoidable.

It is useful to have a working definition of what a picture is and I will propose the following: A picture is produced through establishment of a relation between one space and another so that some spatial properties of the first are preserved in the second, which is its image. A perspective projection is one of many ways this definition may be satisfied (fig. 2).

The definition may be fleshed out, as cartographers do, by exactly stating what properties are preserved, but the basic idea is that, though the defining relation of the layout of the picture may discard some of the original information, this relation is not arbitrary. The challenge in the design of a picture is the decision what to preserve and what to discard.

Artists, of course, have been making these decisions for thousands of years, and we can learn much from this history. One curious aspect of it, one that I certainly found strange when I learned 
of it, is that early art was not focused on the preservation of spatial properties that I have asserted to be the essence of a picture.

As art historians have pointed out, early art was often iconographic, depicting symbols, as these Egyptian symbols for fractions illustrate, rather than aspiring to three-dimensional realism (fig. 3) (Gombrich, 1969). This early history underscores a second aspect of pictures which we must consider: their symbolic content. Because of the potentially arbitrary relation between a symbol and what it denotes, a symbol itself is not a picture. Symbols, nevertheless, have from the very beginning wormed their way into many pictures, and we now must live with both the symbolic and geometric aspects of pictorial communication. Furthermore, the existence of the symbolic content of the picture has the useful role of reminding the viewer of the essentially duplicitous nature of a picture since, though it inherently represents an alternative space, it itself is an object with a flat surface and fixed distance from the viewer.

The third basic element of pictorial communication is computational. The picture must be created. In the past the computation of a picture has primarily been a manual activity limited by the artist's manual dexterity, observational acumen, and pictorial imagination. The computation has two separable parts: 1) the shaping and placement of the components of the image, and 2) the rendering, that is, the coloring and shading of the parts (fig. 4).

While this second part is clearly important and can contribute in a major way to the success of a picture, it is not central to the discussion I wish to develop. Though the rendering of the image can help establish the virtual or illusory space that the picture depicts and can literally make the subject matter reach out of the picture plane, it is not the primary influence on the definition of this virtual space. Shaping and placement are. These elements reflect the underlying geometry used to create the image and determine how the image is to be rendered. By their manipulation artists can define-or confuse - the virtual space conveyed by their pictures.

While the original problems of shaping, positioning, and rendering still remain (figs. 5 and 6), the computation of contemporary pictures is no longer restricted to manual techniques. The introduction of computer technology has enormously expanded the artist's palette, and provided a new 3D canvas on which to create dynamic synthetic universes; yet the perceptual and cognitive limits of the viewers have remained much the same. Thus, there is now a special need for artists, graphic designers, and other creators of pictures for communication to understand these limitations of their viewers. Here is where the scientific interest in the picture of reality and the engineering interest in the picture for communication converge.

\section{SPATIAL INSTRUMENTS}

In order to understand how the spatial information presented in pictures may be communicated, it is helpful to distinguish between images which may be described as spatial displays and those that were designed to be spatial instruments. One may think of a spatial display as any dynamic, synthetic, systematic mapping of one space onto another. A picture or a photograph is a spatial display of an instant of time (fig. 7). A silhouette cast by the sun is not, because it is a natural phenomenon not synthesized by humans. 
A spatial instrument, in contrast, is a spatial display that has been enhanced either by geometric, symbolic, or computational techniques to ensure that the communicative intent of instrument is realized. A simple example of a spatial instrument is an analog clock (fig. 8). In a clock the angular positions of the arms are made proportional to time, and the viewer's angle-estimation task is assisted by radial tic marks designating the hours and minutes.

A second aspect of the definition of a spatial instrument, which the clock example also illustrates, is that the communicated variable-time-is made proportional to a spatial property of the display, such as an angle, areas, or length and is not simply encoded as a character string.

The spatial instruments on which we wish to focus attention are generally interactive. That is to say, the communicated information flows both to and fro between the viewer and the instrument. Some of this bidirectional flow exists for practically all spatial instruments, since movement of the viewer can have a major impact on the appearance of the display. However, the displays I wish to consider are those incorporating at least one controlled element, such as a cursor, which is used to extract information from and input information to the instrument.

Spatial instruments have a long history. One of the first ever made, dating from $60-80 \mathrm{BC}$, was an astrolabe-like device uncovered in 1901 near Antikythera, Greece. However, it was not fully described until the late '50's by De Solla Price (1959), who was able to deduce much of its principles of operation by $\mathrm{x}$-raying the highly corroded remains (fig. 9). Here the communicated variables were the positions of heavenly bodies. Nothing approaching the complexity of this device is known until the 16 th Century. It represents a highly sophisticated technology otherwise unknown in the historical record.

Though many subsequent spatial instruments have been mechanical and, like the Prague town hall clock (fig. 8), have similarly been associated with astronomical calculations (King, 1978), this association is not universal. Maps, when combined with mechanical aids for their use, certainly meet the definition of a spatial instrument (fig. 10). The map projection may be chosen depending upon the spatial property of importance. For example, straight-line mapping of compass courses (rhumb lines), which are curved on many maps, can be preserved in Mercator projections (Dickinson, 1979; Bunge, 1965). Choice of these projections illustrates a geometric enhancement of the map. The overlaying of latitude and longitude lines illustrates a symbolic enhancement (figs. 11-13). But more modern media may also be adapted to enhance the spatial information that they portray, as illustrated by the reference grid used by Muybridge in his photographs (Muybridge, 1975) (fig. 14).

Contemporary spatial instruments are found throughout the modern aircraft cockpit (fig. 15), the most notable probably being the attitude direction indicator which displays a variety of signals related to the aircraft's attitude and orientation. More recent versions of these standard cockpit instruments have been realized with CRT displays, which have generally been modeled after their electromechanical predecessors (Boeing, 1983). But future cockpits promise to look more like offices than anything else (fig. 16). In these offices the computer graphics and CRT display media, however, allow the conception of totally novel display formats for totally new, demanding aerospace applications.

For instance, a pictorial spatial instrument to assist informal, complex, orbital navigation in the vicinity of an orbiting spacecraft has been described (fig. 17) (see also Paper 37, Grunwald and Ellis, 1988). Other graphical visualization aids for docking and orbital maneuvering, as well as 
other applications, have been demonstrated by Eyles (1986) (see also Paper 36). These new instruments can be enhanced in three different ways: geometric, symbolic, or computational.

\section{GEOMETRIC ENHANCEMENT}

In general, there are various kinds of geometric enhancements that may be introduced into spatial displays, but their common feature is a transformation of the metrics of either the displayed space or of the objects it contains. A familiar example is found in relief topographic maps for which it is useful to exaggerate the vertical scale. This technique has also been used for experimental traffic displays for commercial aircraft (fig. 18) (Ellis, McGreevy, and Hitchcock, 1987).

Another type of geometric enhancement important for displays of objects in 3D space involves the choice of the position and orientation of the eye coordinate system used to calculate the projection (fig. 19). Azimuth, elevation, and roll of the system may be selected to project objects of interest with a useful aspect. This selection is particularly important for displays without stereoscopic cues, but all types of displays can benefit from an appropriate selection of these parameters (Ellis et al., 1985; see also Paper 30, Kim et al., 1987).

The introduction of deliberate spatial distortion into a spatial instrument can be a useful way to use geometric enhancement to improve the communication of spatial information to a viewer. The distortion can be used to correct underlying natural biases in spatial judgements. For example, exocentric direction judgements (Howard, 1982) made of extended objects in perspective displays, can, for some response measures, exhibit a "telephoto bias." That is to say, the subjects behave as if they were looking at the display through a telephoto lens. This bias can be corrected by introduction of a compensating wide-angle distortion (McGreevy and Ellis, 1986; Grunwald and Ellis, 1987).

\section{SYMBOLIC ENHANCEMENT}

Symbolic enhancements generally consist of objects, scales, or metrics that are introduced into a display to assist pick-up of the communicated information. The usefulness of such symbolic aids can be seen, for example, in displays to present air traffic situation information which focus attention on the relevant "variables" of a traffic encounter, such as an intruder's relative position, as opposed to less useful "properties" of the aircraft state, such as absolute position (Falzon, 1982).

One way to present an aircraft's position relative to a pilot's own ship on a perspective display is to draw a grid at a fixed altitude below an aircraft symbol and drop reference lines from the symbol onto the grid (fig. 20). If all the displayed aircraft are given predictor vectors that show future position, a similar second reference line can be dropped from the ends of the predictor lines.

The second reference line not only serves to clearly show the aircraft the future position of the aircraft on the grid, but additionally clarifies the symbol's otherwise ambiguous aspect. Interestingly, it can also improve perception of the target's heading difference with a pilot's ownship. This effect has been shown in an experiment examining the effects of reference lines on egocentric perception of azimuth (Ellis, Grunwald, and Velger, 1987). I wish to briefly use this experiment 
as an example of how psychophysical evaluation of images can help improve their information display effectiveness.

In this experiment subjects viewed static perspective projects of aircraft-like symbols elevated at three different levels above a ground reference grid: a low level below the view vector, a middle level colinear with the viewing vector, and a high level above the view vector. The aircraft symbols had straight predictor vectors projecting forward, showing future position. In one condition, reference lines were dropped only from the current aircraft position; in the second, condition lines were dropped from both current and predicted position.

The first result of the experiment was that subjects made substantial errors in their estimation of the azimuth rotation of the aircraft; they generally saw it rotated more towards their frontal plane than it in fact was. The second result was that the error towards the frontal plane for the symbols with one reference line increased as the height of the symbol increased above the grid. Most significantly, however, introduction of the second reference line totally eliminated the effect of height, reducing the azimuth error in some cases almost $50 \%$ (fig. 21 ).

More detailed discussion of this result is beyond the scope of this talk; however, these experimental results show in a concrete way how appropriately chosen symbolic enhancements can provide not only qualitative, but quantitative, improvement in pictorial communication. They also show that appropriate psychophysical investigations can help designers define their spatial instruments.

\section{COMBINED GEOMETRIC AND SYMBOLIC ENHANCEMENTS}

Some enhancements combine both symbolic and geometric elements. One interesting example is provided by techniques connecting the photometric properties of objects or regions in the display with other geometric properties of the objects or regions themselves. Russell and Miles (1987) (see also Paper 48), for example, have controlled the transparency of points in space with the gradient of the density of a distributed component and produced striking visualization of $3 \mathrm{D}$ objects otherwise unavailable. These techniques have been applied to data derived from sequences of MRI or CAT scans and allowed a kind of "electronic dissection" of medical images. Though these techniques can provide absolutely remarkable images, one of the challenges of their use is the introduction of metrical aids to allow the viewer to pick up quantitative information from the photometric transformation (Meagher, 1985, 1987).

\section{COMPUTATIONAL ENHANCEMENTS}

While considerable computation may be involved in the rendering and shading of static pictures, the importance of computational enhancement is also particularly evident for shaping and placing objects in interactive spatial instruments. In principle, if unlimited computational resources were available, no computational enhancements would be needed. The enhancements are necessary because resources must be allocated to ensure that the image is computed in a timely and appropriate manner. 
An example of a computational enhancement can be found in the selection of a type of geometric distortion to use as a geometric enhancement in a head-mounted, virtual-image computer display of the type pioneered by Ivan Sutherland (1970) (fig. 22). Distortions in the imagery used by such displays can be quite useful, since they are one way that the prominence of the components of the image could be controlled.

It is essential, however, that the enhancements operate on the displayed objects before the viewing transformation, because, here the picture of reality collides with a picture for communication. The virtual-image presentation makes the picture appear in some ways like a real space. Accordingly, distorting geometric enhancements that are computed after the viewing transformation can disturb visual-vestibular coordination and produce nausea and disorientation. This disturbance shows how different computational constraints distinguish head-mounted from panel-mounted formats.

A second example of a computational enhancement is shown on the interactive, proximityoperations, orbital planning tool developed by Art Grunwald in our laboratory. When first implemented, the user was given control of the direction and magnitude of the thrust vector; these seemed reasonable, since they are the basic inputs to making an orbital change. The nonlinearities and counterintuitive nature of the dynamics, however, made manual control of a predictor cursor driven by these variables impossible. The computational trick needed to make the display tool work was allowing the user to command that the craft be at a certain location at a set time and allow the computer to calculate the required burns through an inverse orbital dynamics algorithm. This technique provided a good match between the human user's planning abilities and the computer's massive computational capacity.

A third example of a computational enhancement is shown on the same interactive, proximityoperations, orbital planning tool. Despite the fact that the system has been implemented on a highperformance 68020 workstation with floating-point processor and dedicated graphics geometry engine, unworkably long delays would occur if the orbital dynamics were constantly updated while the user adjusted the cursor to plan a new way-point. Accordingly, the dynamics calculations are partially inhibited whenever the cursor is in motion. This feature allows a faster update when the user is setting a way-point position and eliminates what would otherwise be an annoying delay of about $0.3 \mathrm{sec}$ while adjusting the way-point position.

When Arthur Grunwald finished the first iteration of this display, we decided to name it. Like a dutiful NASA researcher, he searched for a acronym-something like Integrated Orbital and Proximity Planning Systems, or IOPPS for short. This looked to me like it might sound like OOPS and I thought we should find a better name. I asked him to find maybe a Hebrew name that would be appropriate. He thought about it for awhile and came up with Navie, or "reliable prophet." This is perfect, since that is exactly what the display is intended to provide: reliable prophesy of future position.

But there is another sense in which Navie is a good name. I would like to think that it, and other display concepts developed in our division and elsewhere, also provide a kind of prophesy for the coming displays to be used by NASA during future unmanned, and manned, exploration of air and space. 
Like most human activities, this exploration is not an endeavor that can be automated; it will require iteration, trial and error, interactive communication between men and machines and between men and other men. The media for this communication must be designed. Some of them will be spatial instruments. 


\section{BIBLIOGRAPHY AND REFERENCES}

Adams, A. (1975). Camera and lens. New York: Morgan and Morgan.

Bertoz, A. and Melville-Jones, G. (1985). Adaptive mechanisms in gaze control: facts and theories. New York: Elsevier.

Boeing (1983). 757/757 Flight deck design development and philosophy, D6T11260-358. Boeing, Seattle.

Bunge, W. (1965). Theoretical Geography, 2nd ed. Studies in Geography, The Netherlands, Lund, Gieerup.

De Solla Price, Derek J. (1959). An ancient greek computer. Sci. Amer., 200, 60-67.

Dickinson, G. C. (1979). Maps and air photographs. New York: Wiley.

Ellis, S. R., Kim, W. S., Tyler, M., McGreevy, M. W., and Stark, L. (1985). Visual enhancements for perspective displays: perspective parameters. Proc. Intern. Conf. Systems, Man, and Cybernetics. IEEE Catalog 85CH2253-3, 815-818.

Ellis, S. R., Kim, W. S., Tyler, M., and Stark, L. (1985). In Proc. 1985 Intern. Conf. Systems, Man, and Cybernetics. New York: IEEE. 815-818.

Ellis, S. R., Grunwald, A., and Velger, M. (1987). Head-mounted spatial instruments: synthetic reality or impossible dream. Proc. 1987 AGARD Symp. "Motion cues in flight simulation and simulator induced sickness," Brussels, Belgium.

Ellis, S. R., McGreevy, M. W., and Hitchcock, R. (1987). Perspective traffic display format and airline pilot traffic avoidance. Human Factors, 29, 371-382.

Ellis, S. R., Smith, S., and McGreevy, M. W. (1987). Distortions of perceived visual directions out of pictures. Perception Psychophys., 42, 535-544.

Ellis, S. R. and Grunwald, A. (1987). A new visual illusion of projected three-dimensional space. NASA TM 100006.

Eyles, D. (1986). Space stations thrillers unfold at Draper Lab. Aerosp. amer., 24, 38-41.

Falzon, P. (1982). Display structures: compatibility with the operators mental representations and reasoning processes. Proc. 2nd European Ann. Conf. Human Decision Making and Manual Contr. Wachtberg-Werthoven, Federal Republic of Germany: Forschungsinstitut für Anthropotechnik. Pp. 297-305.

Fisher, S. S., McGreevy, M. W., Humphries, J., and Robinett, W. (1986). Virtual environment display system. ACM 1986 Workshop on 3D Interactive Graphics, Chapel Hill, NC. 
Foley, J. D. and Van Dam, A. (1982). Fundamentals of interactive computer graphics. Boston: Addison-Wesley.

Gombrich, E. H. (1969). Art and illusion, Princeton, N. J.: Princeton Univ. Press.

Gregory, R. L. (1970). The intelligent eye. New York: McGraw-Hill.

Held, R., Efstathiou, A., and Greene, M. (1966). Adaptation to displaced and delayed visual feedback from the hand. J. Exp. Psychol., 72, 887-891.

Ittelson, W. H. (1951). Size as a cue to distance: static localization. Amer. J. Psychol., 64, 54-67.

Goldstein, E. B. (1987). Spatial layout, orientation relative to the observer, and perceived projection in pictures viewed at an angle. J. Exp. Psychol., 13, 256-266.

Grunwald, A. and Ellis, Stephen R. (1986). Spatial orientation by familiarity cues. Proc. 6th European Ann. Conf. Manual Contr., Univ. Keele, Great Britain.

Grunwald, A. and Ellis, S. R. (1987). Interactive orbital proximity operations planning system. NASA TP-2839.

Helmholtz, H. Handbook of physiological optics (1956-1866). Southall trans., Opt. Soc. Amer. (1924), Rochester, NY.

Herbst, P. J., Wolff, D. E., Ewing, D., and Jones, L. R. (1946). The TELERAN proposal. Electronics, 19, 125-127.

Howard, I. (1982). Human visual orientation. New York: Wiley.

Jenks, G. F. and Brown, D. A. (1966). Three-dimensional map construction. Science, 154, 857-846.

Kim, W. S., Ellis, S. R., Tyler, M., and Hannaford, B. (1987). IE.EE Trans. Man and Cybernetics SMC-17, no. 1, pp. 61-71.

King, H. C. (1978). Geared to the Stars. Toronto: Univ. Toronto Press.

McGreevy, M. W. and Ellis, S. R. (1986). The effects of perspective geometry on judged direction in spatial information instruments. Human Factors, 28, 421-438.

Meagher, D. J. (1985). Surgery by computer. New Scientist, p. 21.

Meagher, D. J. (1987). Manipulation analysis and display of 3D medical objects using octtree encoding. Innov. Tech. Biol. Med., 8, $\mathrm{n}^{\circ}$ special 1.

Muybridge, Edward (1975). Animals in Motion, Lewis S. Brown, ed. New York: Dover. 
Nagata, S. (1986). How to reinforce perception of depth in single two-dimensional pictures. Selected papers in basic researchers, No. 44-51, Proc. 1984 SID, 25, 239-246.

Parker, D. E., Renschke, M. F., Arrott, A. P., Homick, J., and Lichtenberg, B. (1986). Otolyth tilt-translation reinterpretation following prolonger weightlessness: implications for preflight training. Avia., Space, Environ. Med., 56, 601-606.

Piaget, J. and Inhelder, B. (1956). The child's conception of space. London: Routledge and Kegan Paul.

Roscoe, S. N. (1984). Judgements of size and distance with imaging displays. Human Factors, 26, 617-629.

Roscoe, S. N. (1987). The trouble with HUDs and HMDs. Human Factors Soc. Bull., 30, 7 , 1-3.

Russell, G. and Miles, R. B. (1987). Display and perception of 3-D space-filling data. Appl. Opt., 26, 973-982.

Sutherland, I. E. (1970). Computer displays. Sci. Amer., 222, 57-81.

Weintraub, D. J., Haines, R. F., and Randle, R. J. (1985). Head up display: HUD utility II: runway to HUD. Proc. 29th Meeting Human Factors Soc. Univ. Michigan, Ann Arbor. 


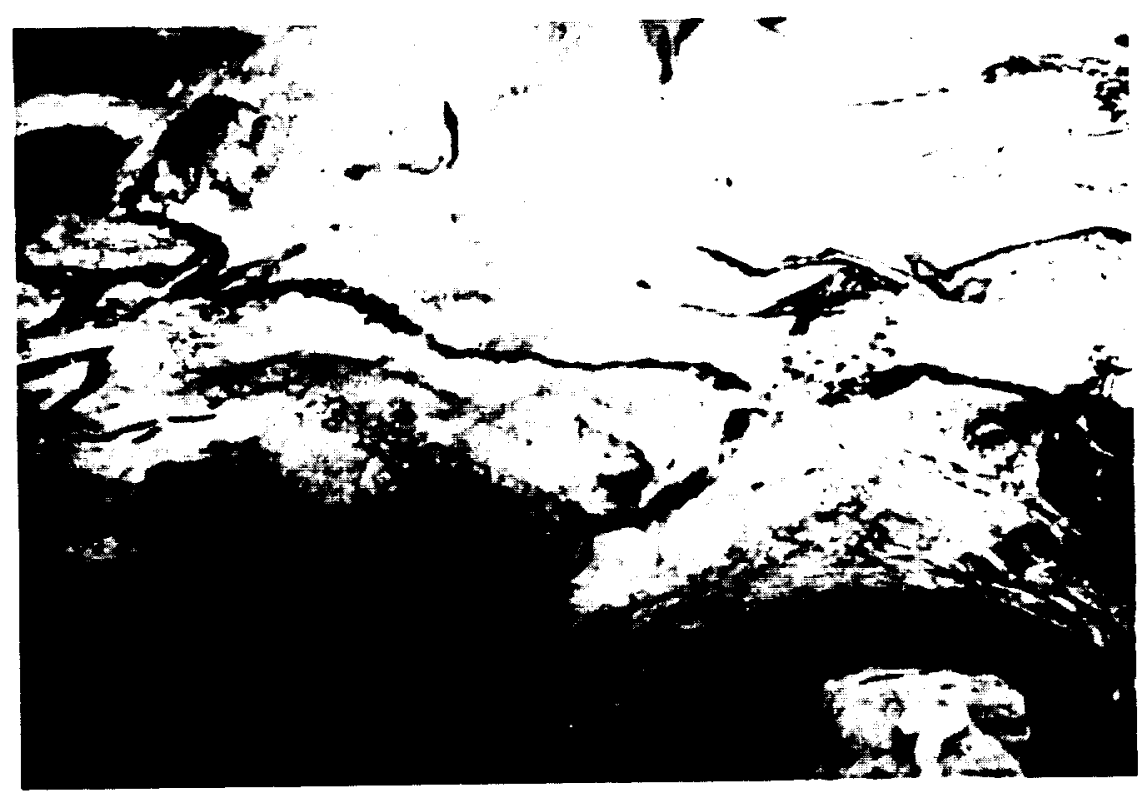

Figure 1.- Prehistoric cave painting of animals from southwestern France.
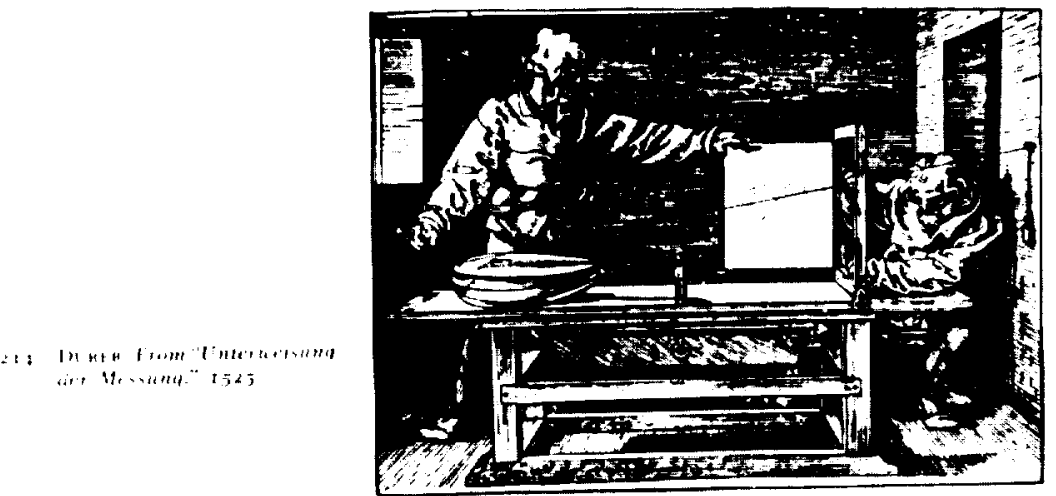

Figure 2.- Woodcut by Dürer illustrating how to plot lines of sight with string in order to make a correct perspective projective. 


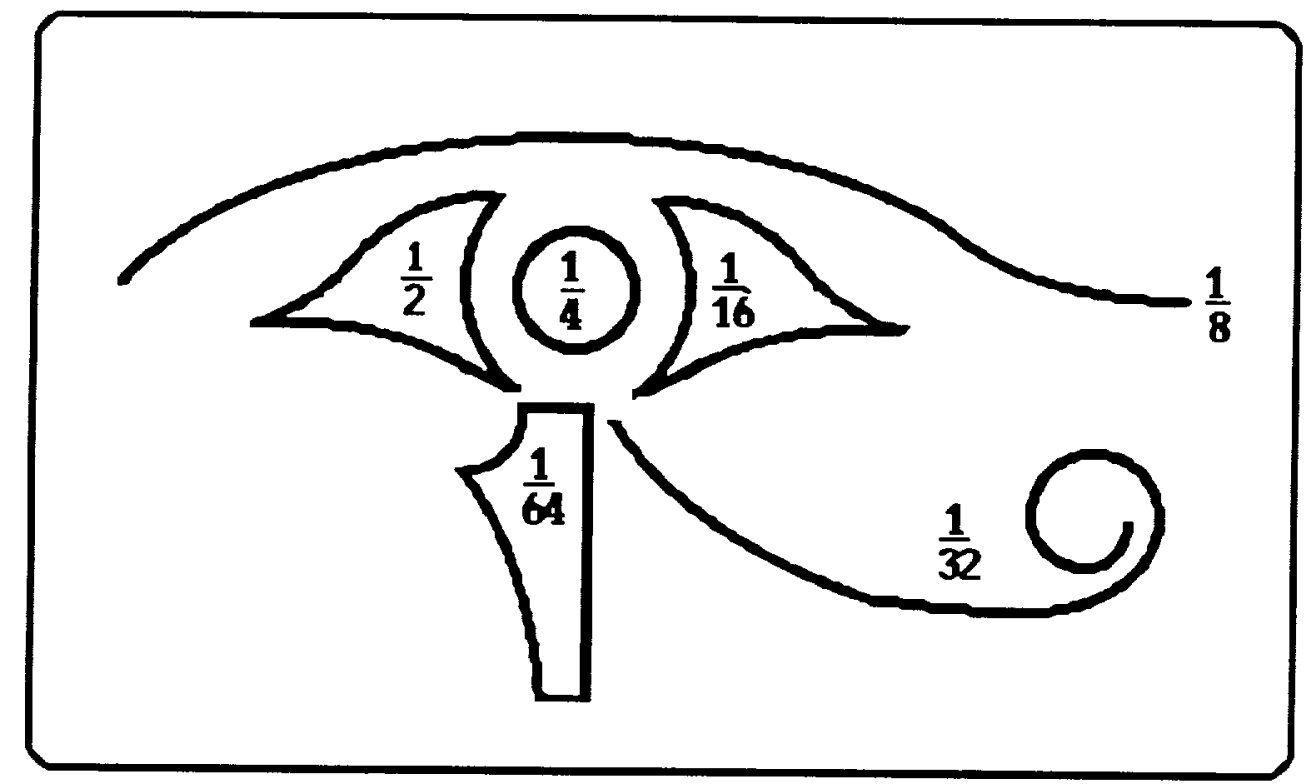

Figure 3.- Egyptian hieroglyphic for the Eye of Horus illustrating the symbolic aspect of pictographs. Each part of the eye is also a symbol for a commonly used fraction. These assignments follow from a myth in which the Sun, represented by the eye, was torn to pieces by the God of Darkness later to be reassembled by Thoth, the God of Learning.

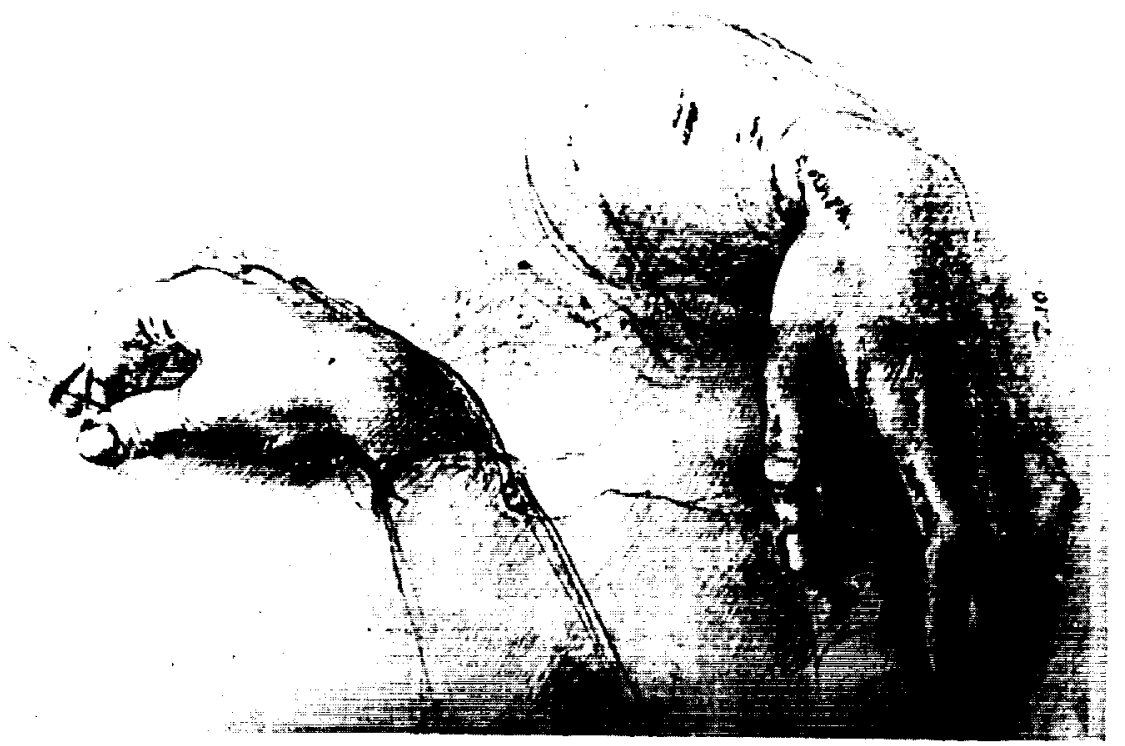

Figure 4.- Leonardo's sketch of two hands using shading to depict depth. 


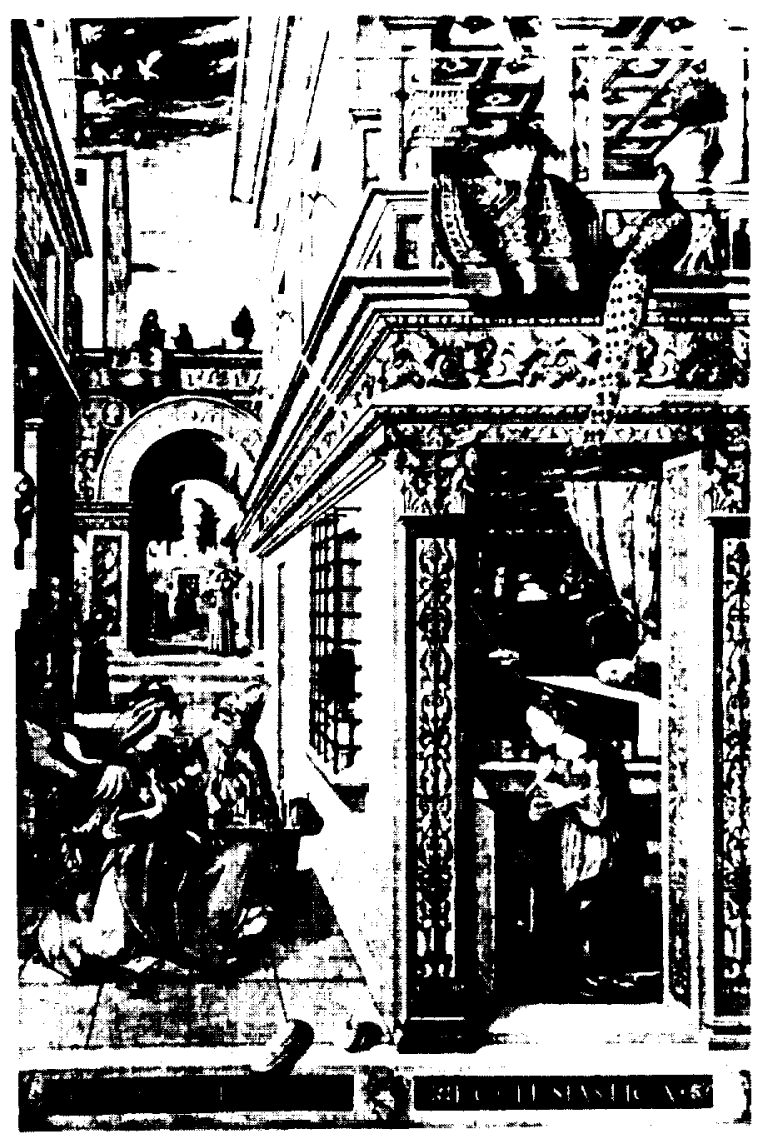

Figure 5.- Crivelli's Annunciation illustrating strong perspective convergence associated with wide-angle views that can exaggerate the range of depth perceived in a picture. 


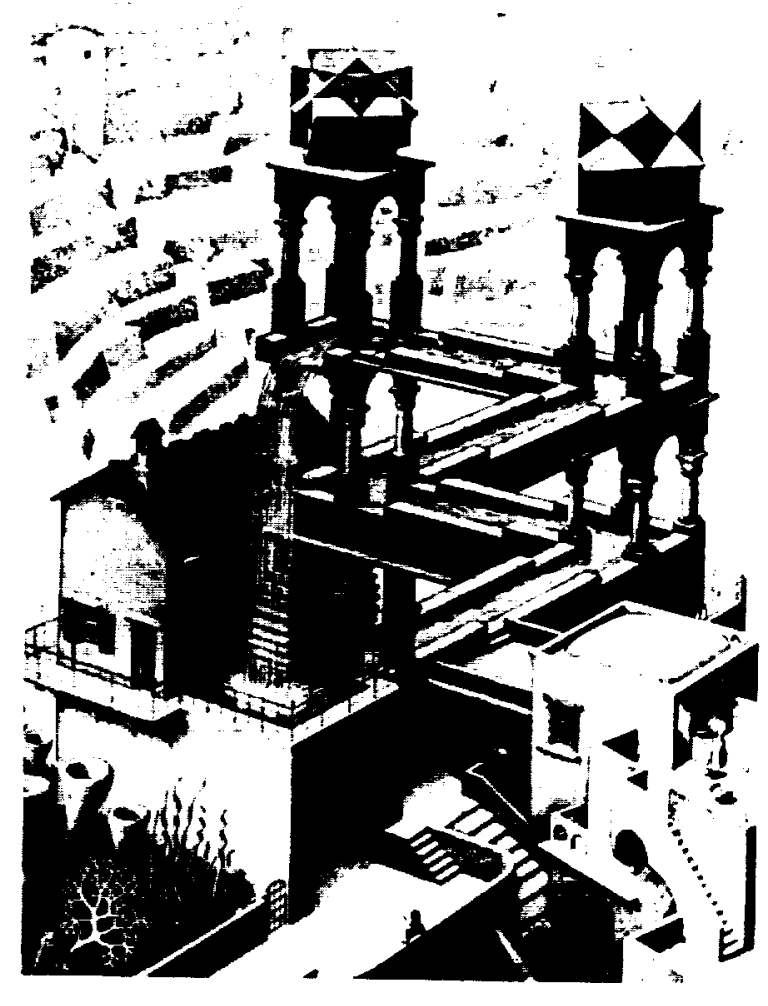

Figure 6.- An engraving by Escher illustrating how the ambiguity of depicted height and depicted depth can be used in a picture to create an impossible structure, apparently allowing water to run uphill. (c) 1988 M. C. Escher heirs/Cordon Art-Baarn-Holland. 


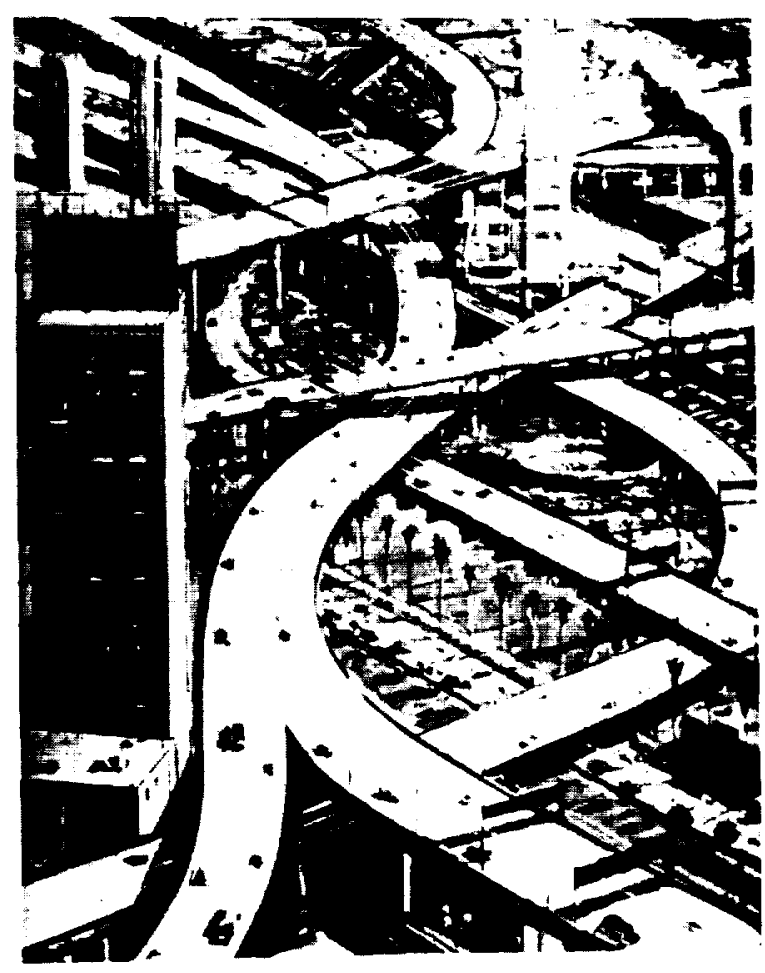

Figure 7.- Urban freeways, a painting by Thiebaud showing an instant of time on a California freeway. 


\section{ORIGINAL PAGE \\ BLACK AND VHUTE PHOTOGRAPH}

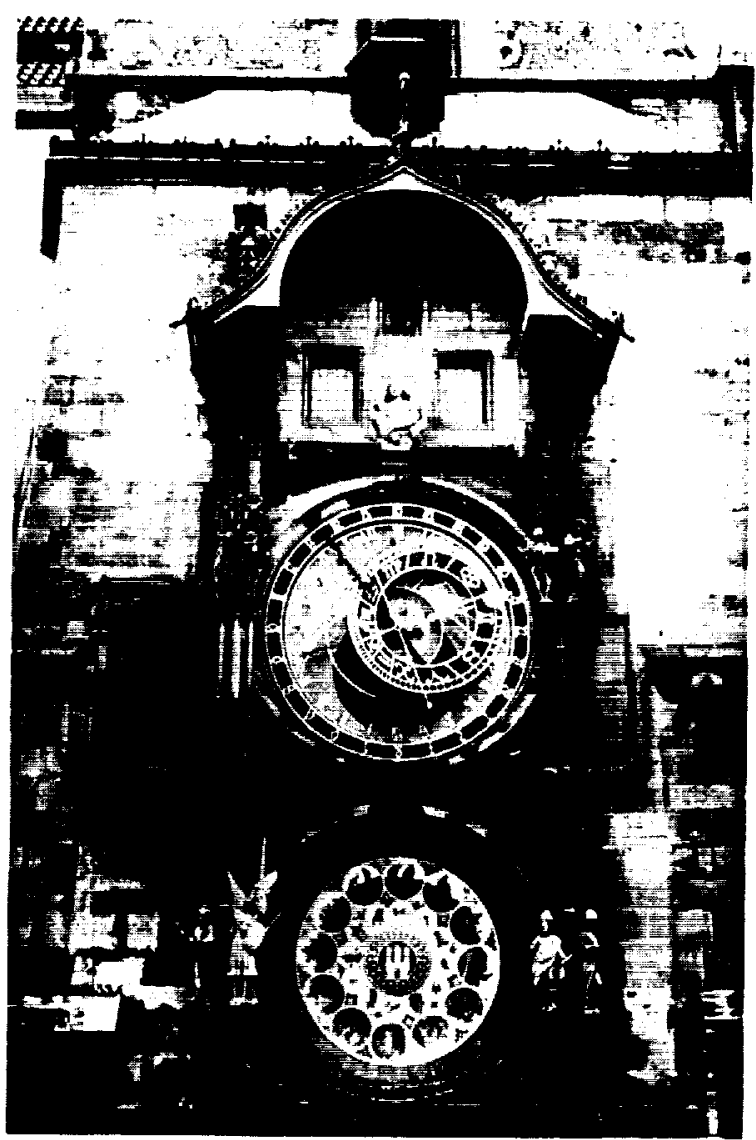

Figure 8.- View of the Prague town hall clock, which indicates the positions of heavenly bodies as well as the time. 

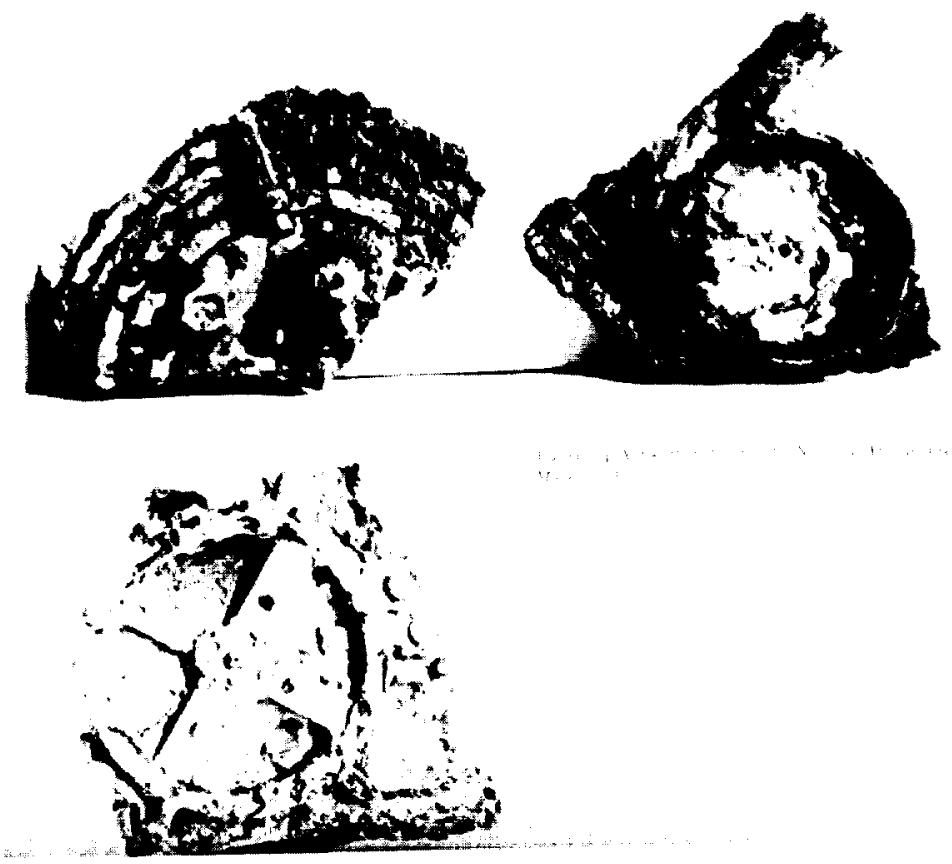

Figure 9.- Fragments of an ancient Greek mechanical device used to calculate the display positions of heavenly bodies.

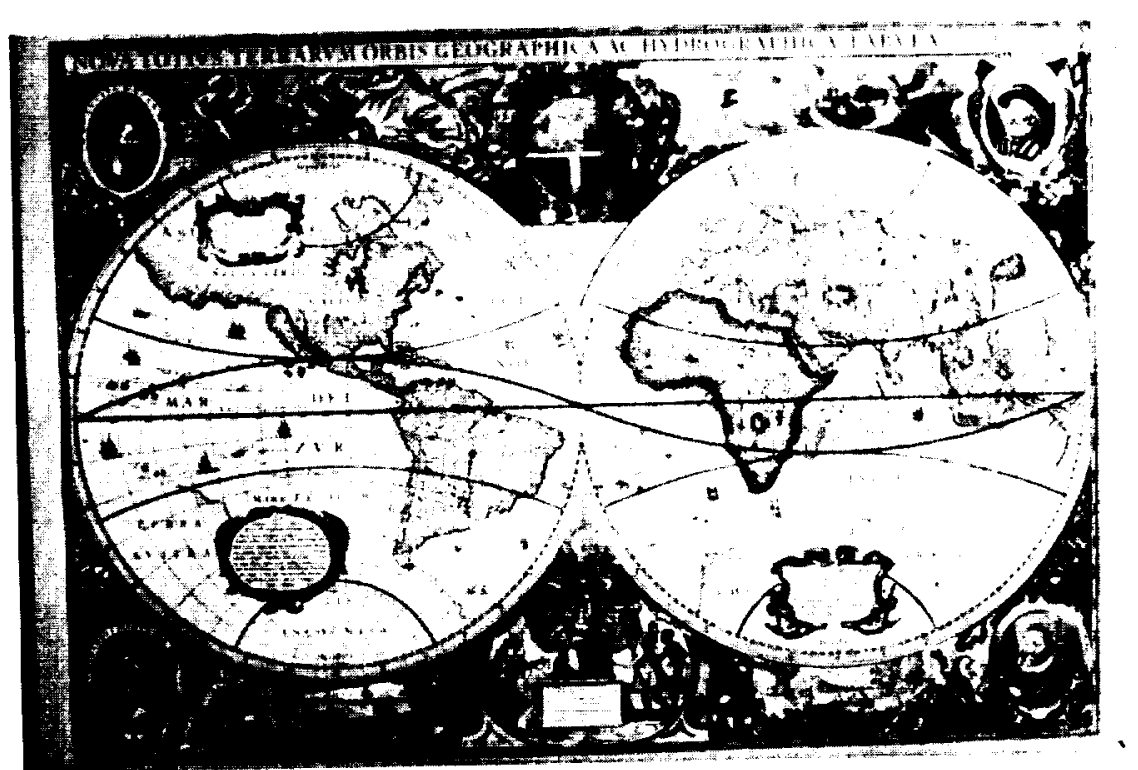

Figure 10.- An old map of the world from the 17th Century.

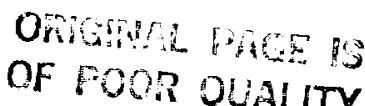

ORIGINAL PAGE

BLACK AND WHITE PHOTOGRAPH 


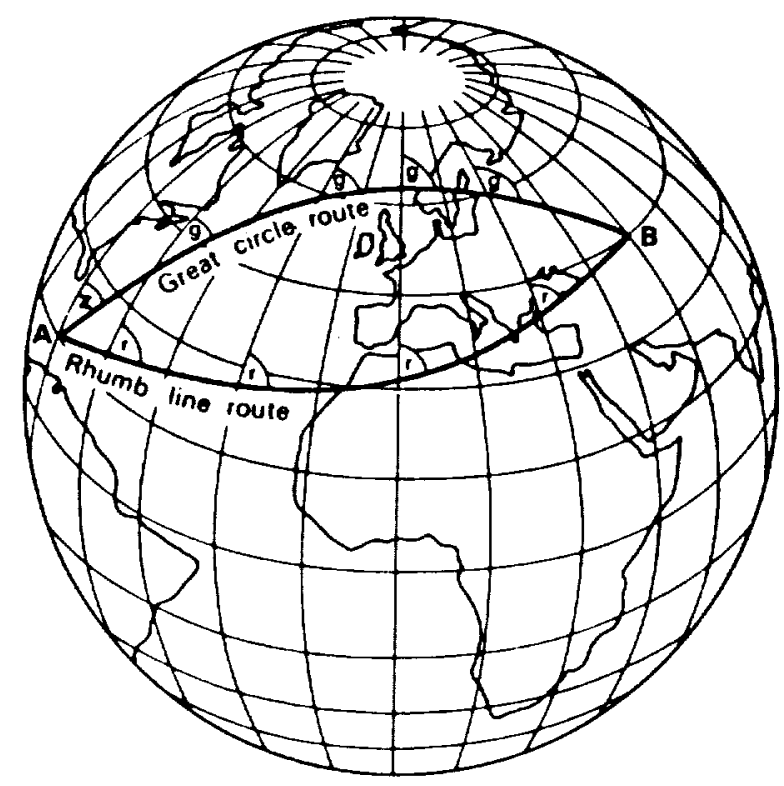

Figure 11.- Rhumb-line and great-circle routes between two points on the globe. Note the constant bearing of the rhumb-line route and the constantly changing bearing of the great-circle route. On the globe the great-circle route is analogous to a straight line and direction $\mathrm{Z}$ is the azimuth of $\mathrm{B}$ from $\mathrm{A}$.

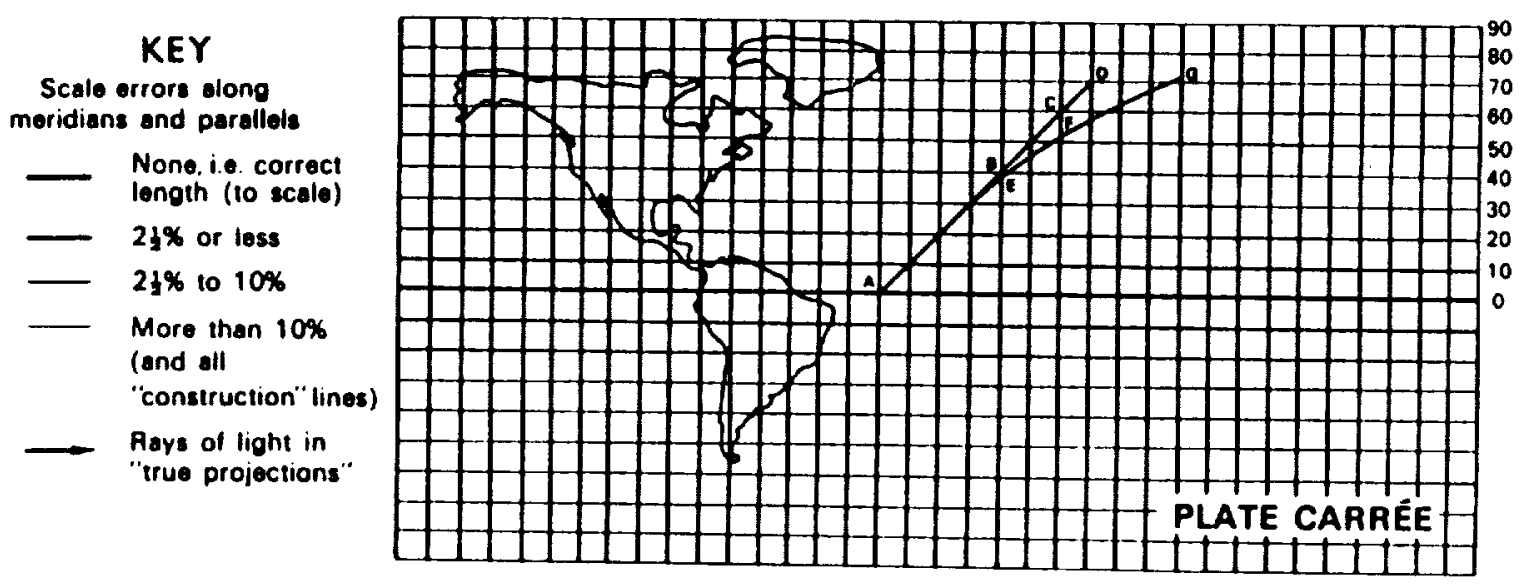

Figure 12.- Plate caree projection illustrating the curved path traced by a rhumb line on this format, i.e., line $\mathrm{AEFG}$. 


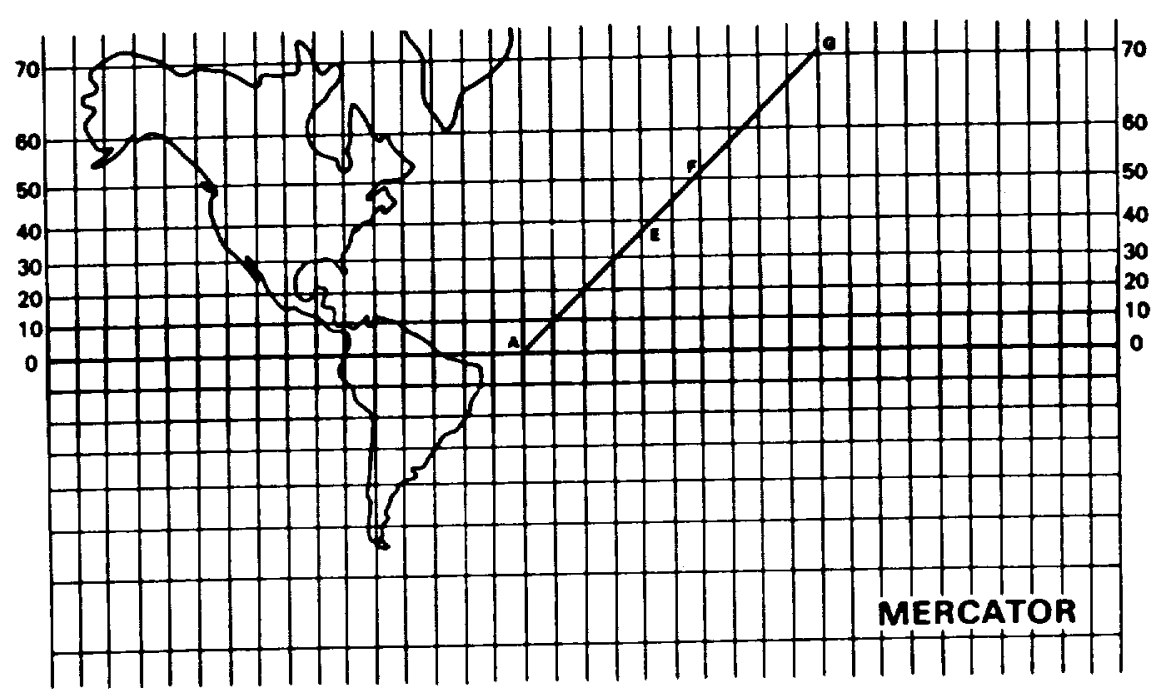

Figure 13.- Mercator projection illustrating how a nonlinear distortion of the latitude scale can be used to straighten out the path traced by a rhumb line.

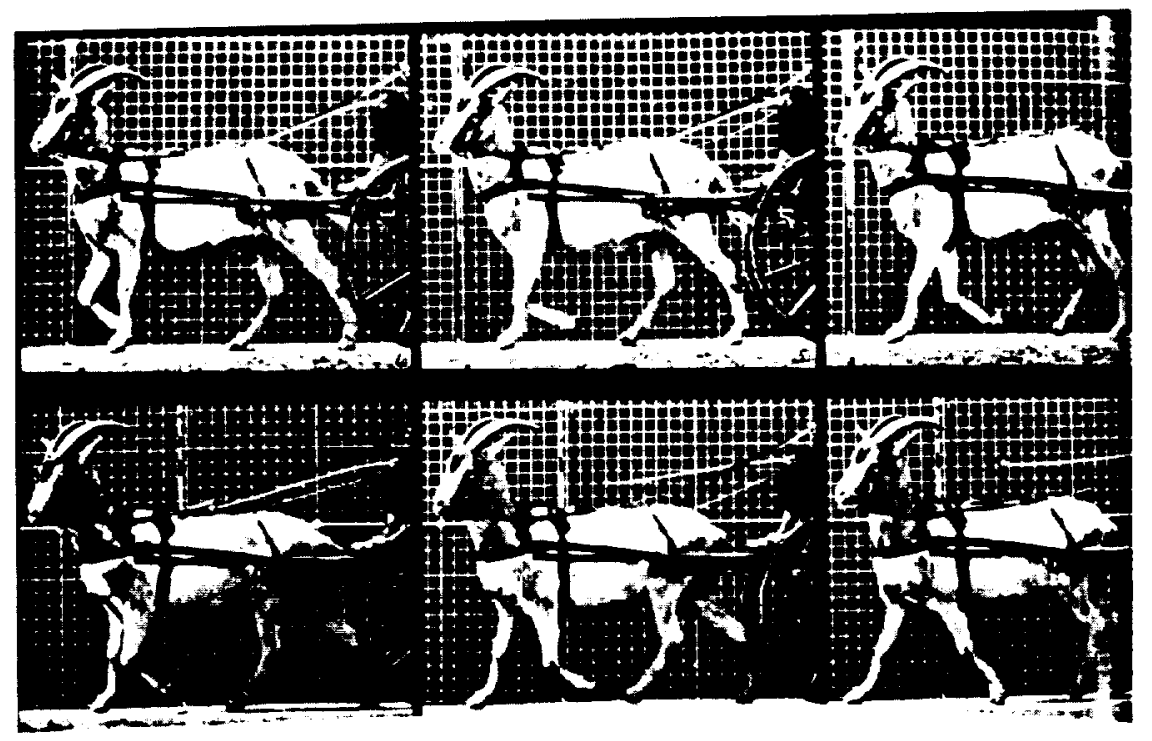

Figure 14.- Muybridge's photographic sequence of a goat walking. The background grid provides a reference for measuring the pattern of limb movement. 


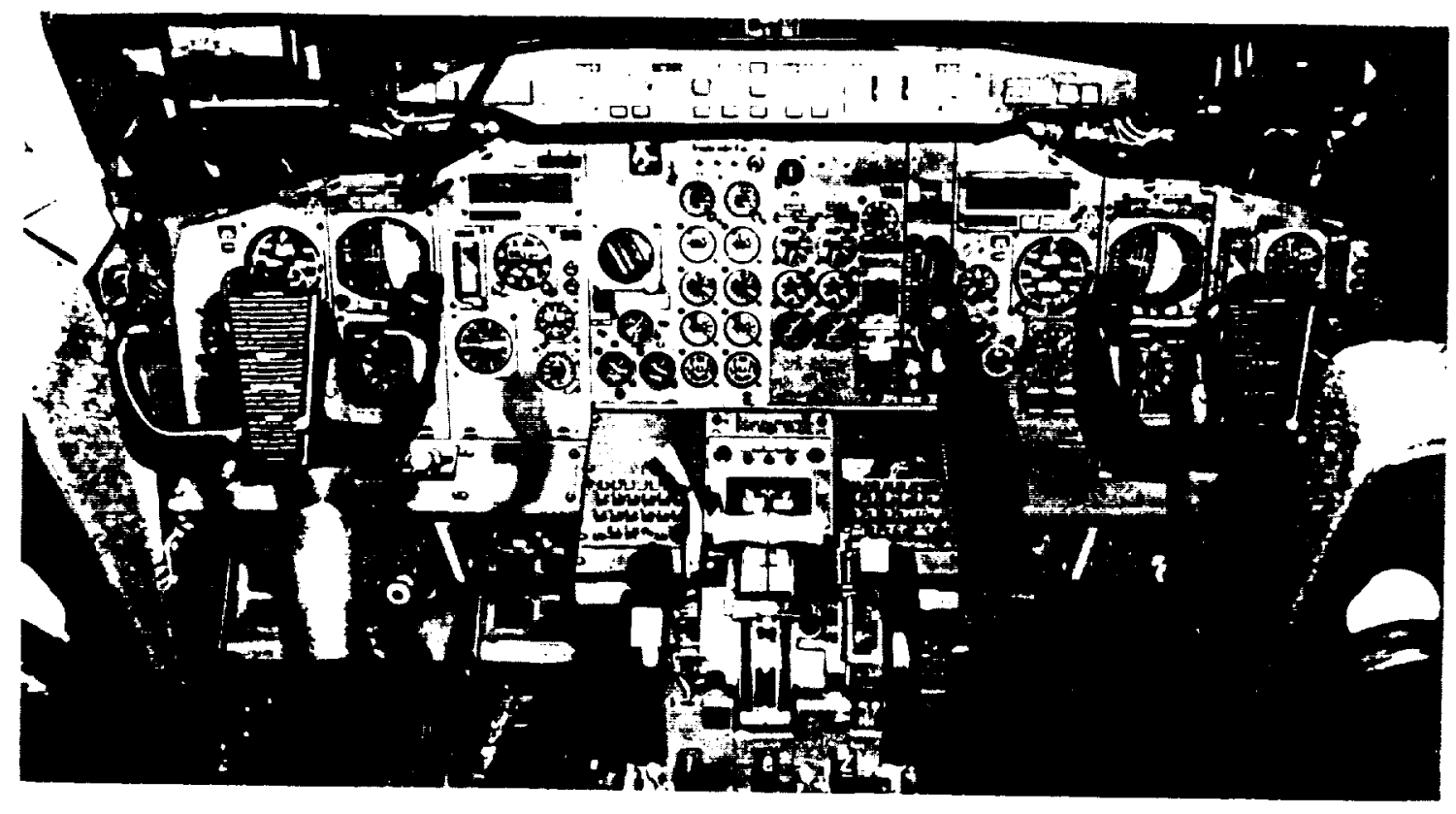

Figure 15.- View of the forward panel of a 737 cockpit showing the artificial horizon on the attitude direction indicator.

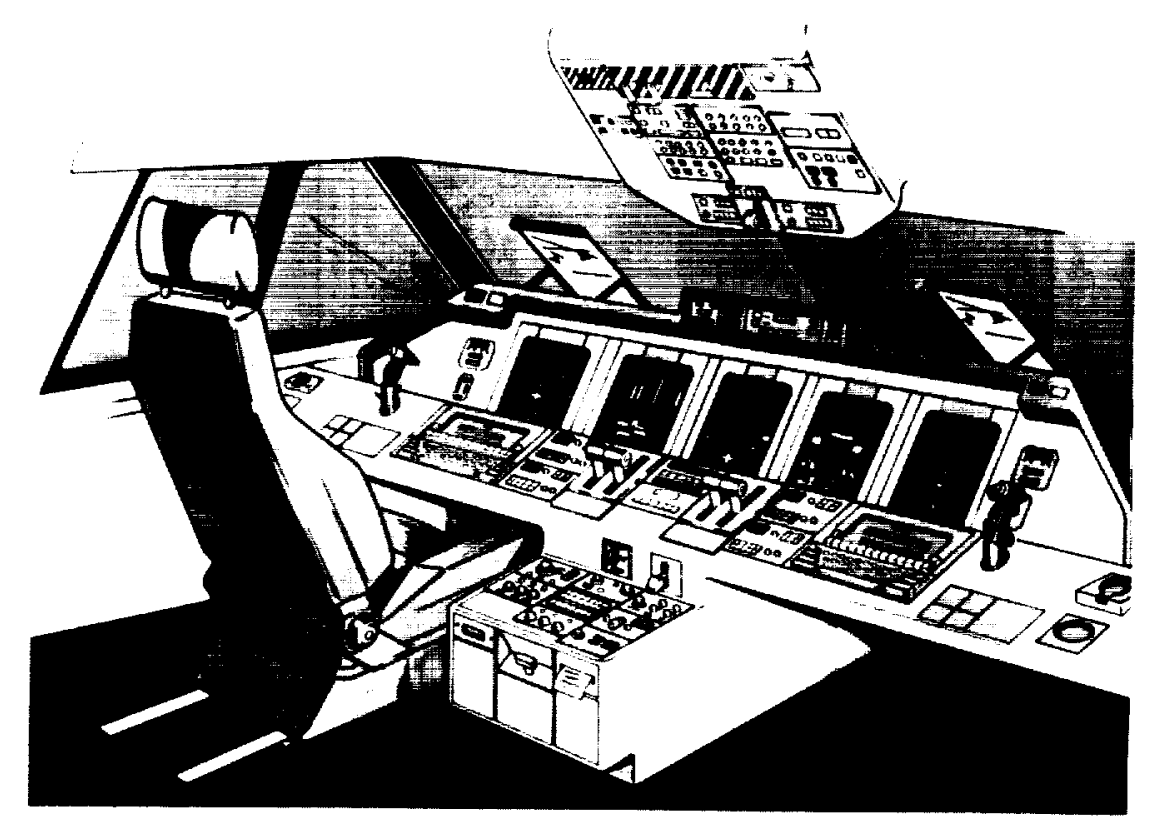

Figure 16.- An advanced-concepts commercial aircraft cockpit in the Man-Vehicle Systems

Research Facility of NASA Ames Research Center. This artist's conception shows how future cockpits may resemble ordinary offices. 


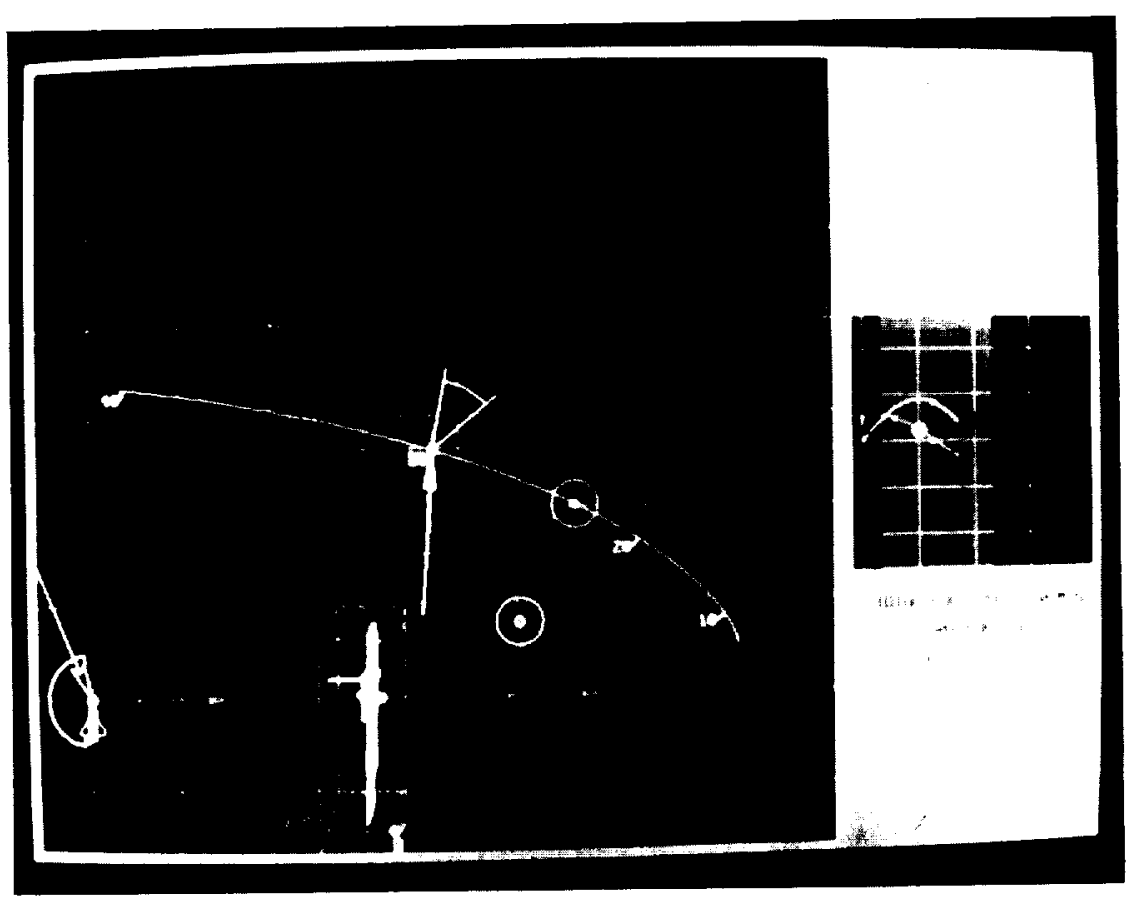

Figure 17.- Sample view from an interactive-graphics-based, planning tool to be used in assisting informal changes in orbits and proximity operations in the vicinity of a space station.

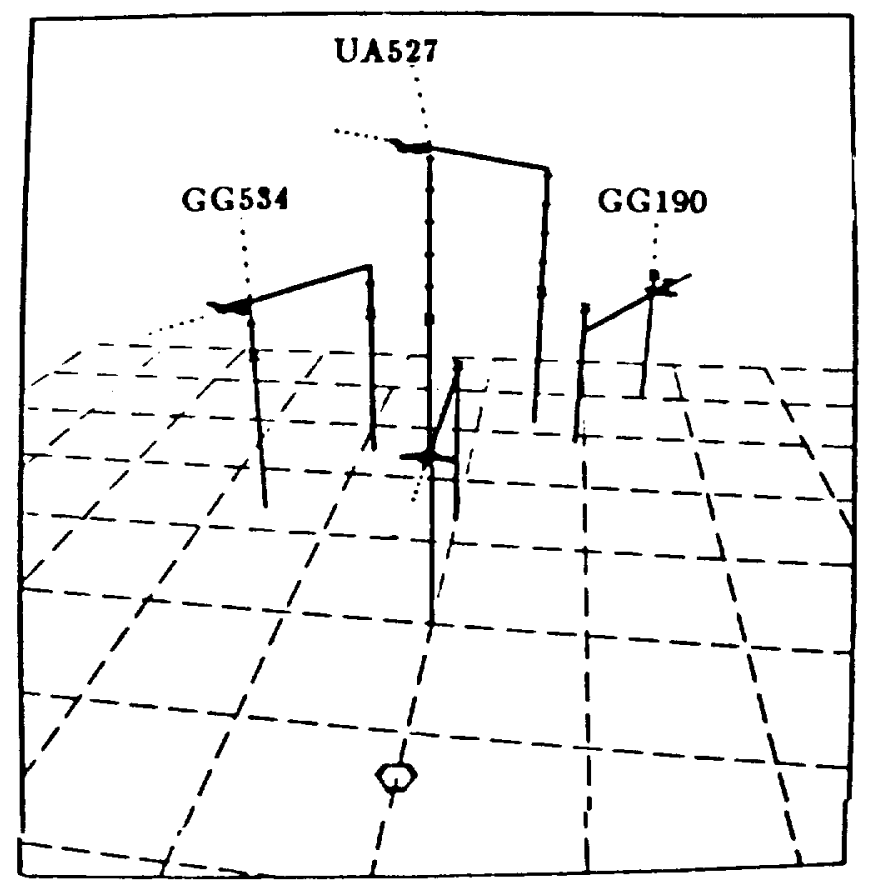

Figure 18.- Possible display format for a commercial aircraft cockpit traffic display. The pilot's own craft is shown in the center of the display. All aircraft have predictor vectors attached showing future position and have reference lines to indicate height above a reference grid. 


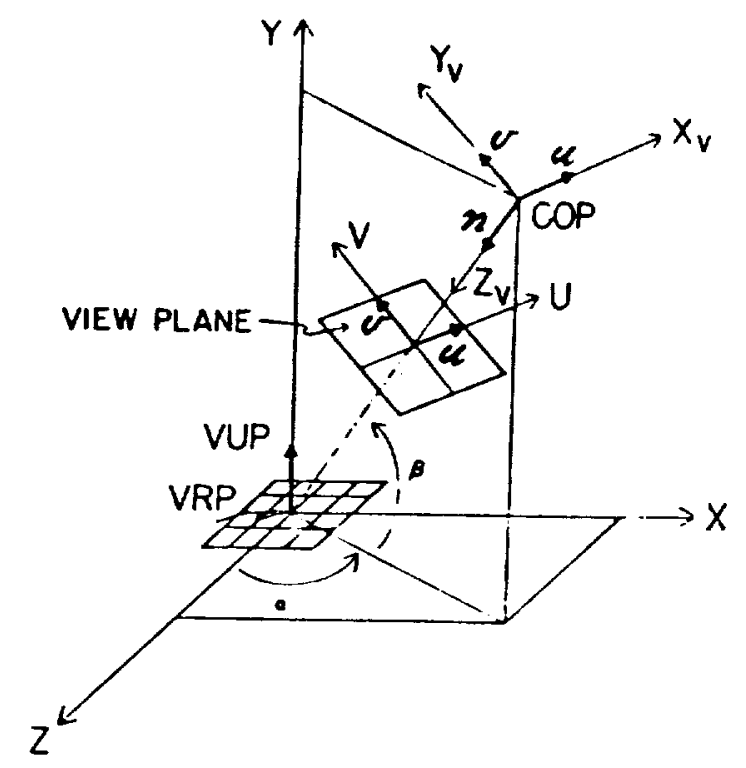

Figure 19.- Illustration of the geometry of perspective projection showing the azimuth and the elevation of the viewing vector InR, directed from the center of projection COP.

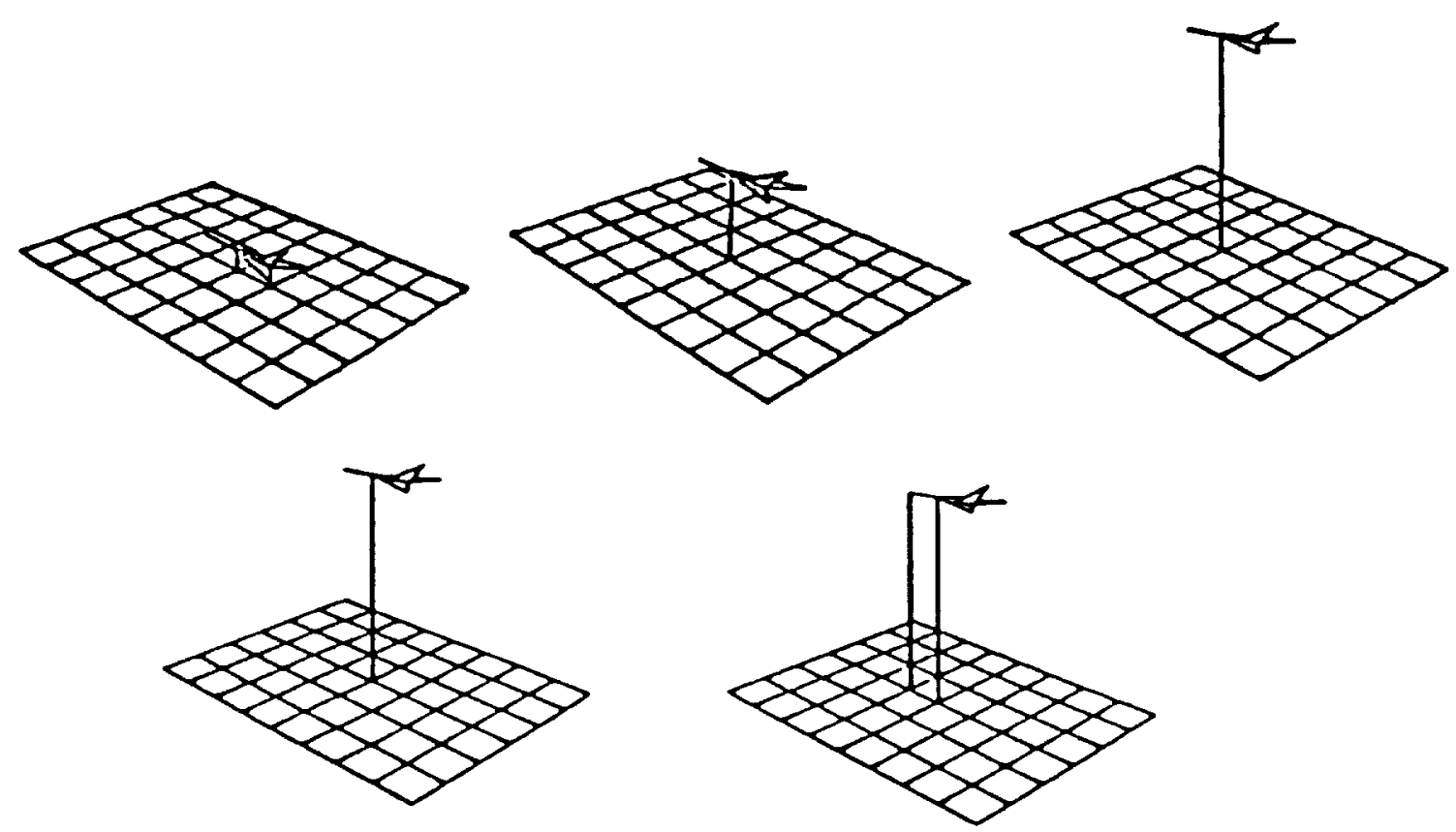

Figure 20.- Five views of sample stimuli used to examine the perceptual effect of raising an aircraft symbol above a reference grid. The attitude of the symbol is kept constant. Addition of a second vertical reference line is seen to reduce the illusory rotation caused by the increasing
height above of the grid. 


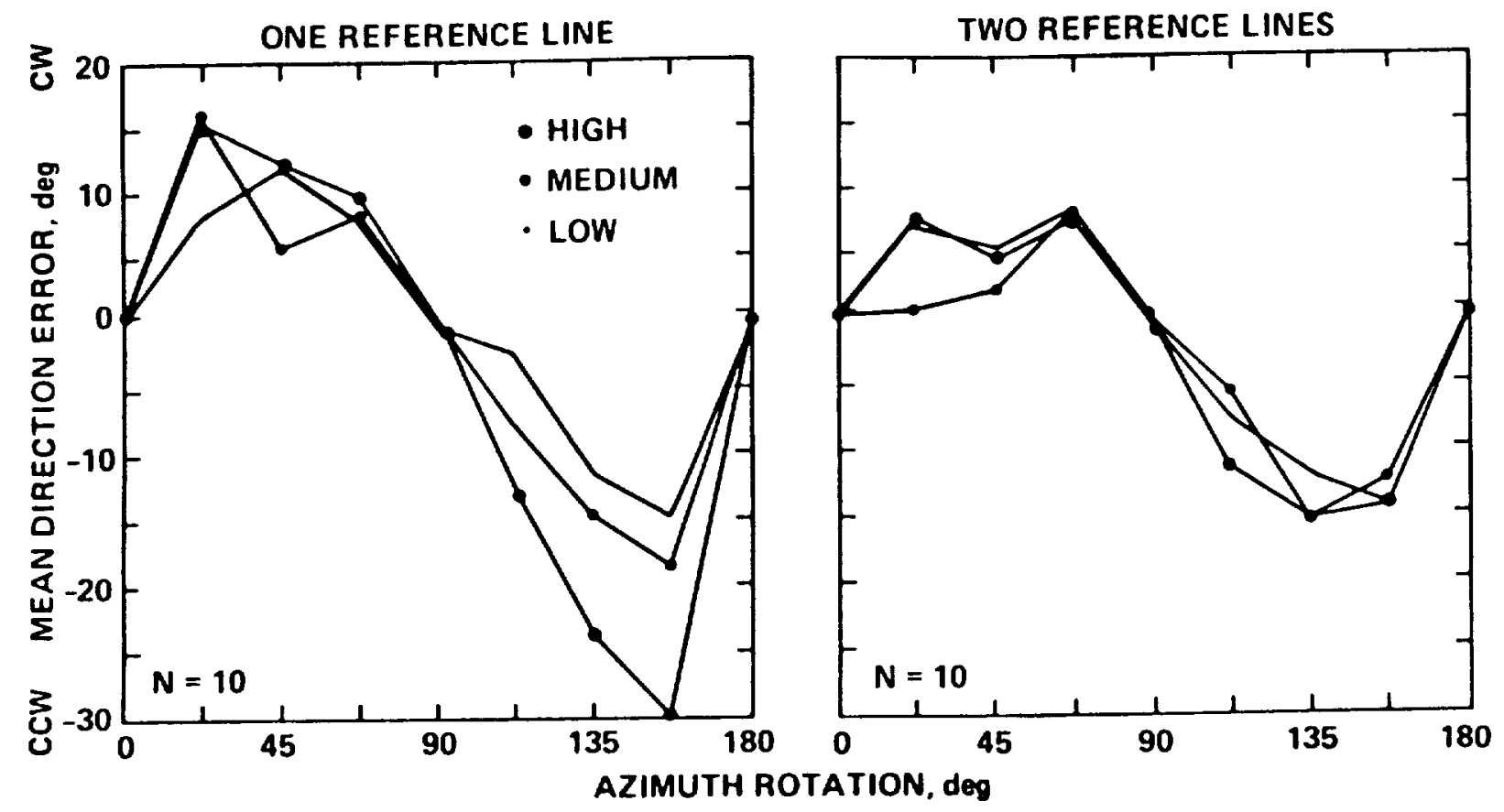

Figure 21.- Mean clockwise and counterclockwise egocentric direction judgement for clockwise azimuth rotation of an aircraft symbol.

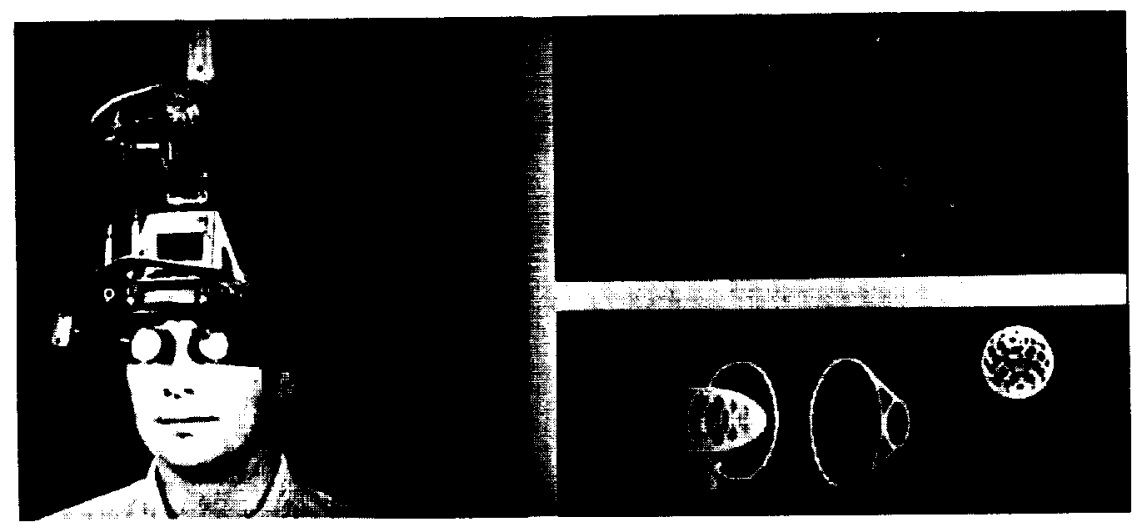

Figure 22.- Probably the first computer-driven head-mounted viewing device. It was developed by Ivan Sutherland to give the viewer the illusion of actually being in the synthetic world defined in the computer.

\author{
ORIGINAL: PAGE \\ BLACK AND WHITE PHOJOGRAPH
}


